\title{
ReCOV: recovery and rehabilitation during and after COVID-19 - a study protocol of a longitudinal observational study on patients, next of kin and health care staff
}

\author{
E. Rydwik' ${ }^{1,2^{*}}$ (D, L. Anmyr $r^{3,4}$, M. Regardt ${ }^{2,5}$, A. McAllister ${ }^{6,7}$, R. Zarenoe ${ }^{3}$, E. Åkerman ${ }^{8,9}$, Y. Orrevall ${ }^{10,11}$, \\ M. Bragesjö ${ }^{12,13}$, O. Dahl ${ }^{8,9}$, M. K. Kemani ${ }^{13,14}$, L. Nordstrand ${ }^{5,13}$, U. Ekman ${ }^{13,15}$, L. Holmström ${ }^{12,13}$ and \\ M. Nygren-Bonnier ${ }^{1,2}$
}

\begin{abstract}
Background: The knowledge of the long-term consequences of covid-19 is limited. In patients, symptoms such as fatigue, decreased physical, psychological, and cognitive function, and nutritional problems have been reported. How the disease has affected next of kin, as well as staff involved in the care of patients with covid-19, is also largely unknown. The overall aim of this study is therefore three-fold: (1) to describe and evaluate predictors of patient recovery, the type of rehabilitation received and patients' experiences of specialized rehabilitation following COVID-19 infection; (2) to study how next of kin experienced the hospital care of their relative and their experiences of the psychosocial support they received as well as their psychological wellbeing; (3) to describe experiences of caring for patients with COVID-19 and evaluate psychological wellbeing, coping mechanisms and predictors for development of psychological distress over time in health care staff.

Methods: This observational longitudinal study consists of three cohorts; patients, next of kin, and health care staff. The assessments for the patients consist of physical tests (lung function, muscle strength, physical capacity) and questionnaires (communication and swallowing, nutritional status, hearing, activities of daily living, physical activity, fatigue, cognition) longitudinally at 3, 6 and 12 months. Patient records auditing (care, rehabilitation) will be done retrospectively at 12 months. Patients (3, 6 and 12 months), next of kin ( 6 months) and health care staff (baseline, 3, 6, 9 and 12 months) will receive questionnaires regarding, health-related quality of life, depression, anxiety, sleeping disorders, and post-traumatic stress. Staff will also answer questionnaires about burnout and coping strategies. Interviews will be conducted in all three cohorts.
\end{abstract}

\footnotetext{
* Correspondence: elisabeth.rydwik@ki.se

'Department of Neurobiology, Care Sciences and Society, Division of Physiotherapy, Karolinska Institutet, Huddinge, Sweden

${ }^{2}$ Women's Health and Allied Health Professionals Theme, Medical Unit Occupational Therapy and Physiotherapy, Karolinska University Hospital, Solna, Sweden

Full list of author information is available at the end of the article
}

(c) The Author(s). 2021 Open Access This article is licensed under a Creative Commons Attribution 4.0 International License, which permits use, sharing, adaptation, distribution and reproduction in any medium or format, as long as you give appropriate credit to the original author(s) and the source, provide a link to the Creative Commons licence, and indicate if changes were made. The images or other third party material in this article are included in the article's Creative Commons licence, unless indicated otherwise in a credit line to the material. If material is not included in the article's Creative Commons licence and your intended use is not permitted by statutory regulation or exceeds the permitted use, you will need to obtain permission directly from the copyright holder. To view a copy of this licence, visit http://creativecommons.org/licenses/by/4.0/ The Creative Commons Public Domain Dedication waiver (http://creativecommons.org/publicdomain/zero/1.0/) applies to the data made available in this article, unless otherwise stated in a credit line to the data. 
Discussion: This study will be able to answer different research questions from a quantitative and qualitative perspective, by describing and evaluating long-term consequences and their associations with recovery, as well as exploring patients', next of kins' and staffs' views and experiences of the disease and its consequences. This will form a base for a deeper and better understanding of the consequences of the disease from different perspectives as well as helping the society to better prepare for a future pandemic.

Keywords: Infection, Physical function, Well-being

\section{Background}

COVID-19 was declared a global pandemic in March 2020 by the World Health Organisation (WHO) [1]. So far (May, 2021), there are over 1000,000 confirmed cases and more than 14,000 deaths in Sweden [2]. Initially, it was assumed that COVID-19 would primarily affect the airways, but several studies have now shown that it is an infection with multisystem manifestations. The impact of the virus ranges from an asymptomatic infection to a very severe illness and signs and symptoms may arise from the cardiac, renal gastrointestinal, nervous, endocrine, and musculoskeletal systems and may change over time [3, 4]. Therefore, COVID-19 has the potential to affect physical, cognitive, and psychological functions in multiple ways. It has been clear that a significant proportion of patients with COVID-19 develop long-term symptoms [3-10].

Previous research has shown that a prolonged stay at an intensive care unit (ICU) is associated with a significant negative impact on lung function, voice function, nutritional status and physical function, intensive care delirium and decreased psychological health. These symptoms can persist and have a negative impact on quality of life in the long-term perspective $[5,6,11]$. However, post-acute COVID-19 symptoms may also occur after so-called mild COVID-19 [5]. An increasing number of patients that never required hospitalization during their COVID-19 illness are displaying the same long-term symptoms, of varying severity, involving several organ systems similar to hospital treated patients $[6,7,11]$. These long-term symptoms in non-hospitalized patients have significant impact on their performance of daily activities as well as the ability to return to work [7, 11]. In addition, impaired physical and psychological function as well as varying degrees of fatigue and cognitive impairment can led to a decreased health-related quality of life [4-7].

Due to the isolation of patients and not allowing visits from relatives, specific telephone lines for relatives were created at Karolinska University Hospital in Stockholm to relieve the staff at the wards; something that has never been done in Sweden before. The support line was staffed by medical social workers, two psychologists and a nurse and were open during days and evenings, 7 days a week. The medical social workers proactively contacted relatives after the patients had been admitted to the hospital, to offer support to their relatives regarding socialand psychosocial situation, and a social anamnesis was obtained. The medical social workers also contacted relatives in the event of death. At first, relatives were given the opportunity to say a final farewell via digital media when the patients were in the end-of-life stage, but at the end of wave 1, relatives could visit for a final farewell. Few studies exist regarding this type of support for relatives in similar situations. During the SARS epidemic in Hong Kong, a "hotline" and a help desk were staffed where relatives could turn for support and information [12]. The intervention was only evaluated through a short questionnaire that was handed out to close relatives who used the helpdesk function for a week. The results were positive, but what the residual effect may be remains unanswered. One function that was requested for the future was the possibility of communication via digital media.

Karolinska University Hospital has cared for the largest number of patients with severe COVID-19 in Sweden during 2020. The hospital's employees have worked under extraordinary conditions, which has raised concerns about lack of protective equipment, long work shifts, high workload, moral stress, fear of infection, exposure to potentially traumatic experiences and lack of opportunities for recovery. In a study published early in the ongoing pandemic, the results showed that health care professionals in close contact with patients with COVID-19 in Wuhan, and other severely affected regions of China, reported major psychological strains, including depression, anxiety, difficulty sleeping and post-traumatic stress symptoms $[13,14]$. Similar reports, on short term psychological distress in health care staff have also been published from Italy and the US during the spring [15-17]. Previous experiences from the SARS epidemic in 2003 show that in addition to developing disorders in the short term, healthcare professionals also risk long-term psychological distress. Long-term follow-up, up to 2 years after the SARS epidemic showed that healthcare professionals caring for critically ill patients had an increased risk of burnout, anxiety, post-traumatic stress disorder and short-term sick leave compared to healthcare professionals from a nearby city not affected by the virus to the same extent $[18,19]$. 
In summary, the knowledge of consequences of being severely ill and treated in hospital, with or without intensive care due to COVID-19 is limited. Consequences such as fatigue, decreased physical and psychological function have been reported, but little is known of the long-term consequences. How the pandemic has affected next of kin and staff are also at large unknown.

This observational and longitudinal study consists of three cohorts; patients, next of kin (both those where their relative survived and those that lost their relative), and health care staff (Fig. 1).

Based on these three cohorts, the overall aims of this project are:

- to evaluate recovery and predictors of recovery in multiple health related areas such as physical function, cognition, fatigue, health-related quality of life and psychological health at 3, 6 and 12 months for patients with COVID - 19. The aim is also to describe type of care and rehabilitation as well as to explore how patients experienced their disease period and the care and rehabilitation they received.

- to study the psychological health of next of kin and how they experienced the hospital care and their experiences of the psychosocial support they received as well as communication with their relative and the staff.

- to describe experiences of caring for patients with COVID-19 and evaluate psychological wellbeing, coping mechanisms and predictors for development of psychological distress over time in health care staff.

\section{Methods}

This study is a collaboration between the departments of Allied Health Professionals, Infection, Respiratory Medicine,
Cardiology, Radiology and Intensive Care at the Karolinska University Hospital in Stockholm, Sweden.

The study will collect both quantitative and qualitative data. Quantitative data will be collected in an observational study with an explorative hypothesis-generating design in three cohorts. To capture experiences from patients, next of kin and health care staff, a qualitative design will be used. The designs in the different cohorts are described below and an overview is shown in Fig. 1.

\section{The patient cohort}

This cohort include two groups, those that have been hospitalized and those who have been referred from primary care to the out-patient clinic due to long-term symptoms but were never hospitalized during the infection. The test battery consists of physical tests and screening, questionnaires, and interviews as well as patient records auditing (Table 1). The hospitalized patients will be followed longitudinally at 3, 6 and 12 months after discharge at an out-patient clinic at the hospital. At 12 months a retrospective auditing of patients' record will be done to evaluate type and the effects of specialized rehabilitation during and after discharge (Fig. 2).

Patients above the age of 18 that are referred to the out-patient clinic will be asked to participate in the research project. This includes the following groups: 1 ) patients that have been hospitalized, age $>18$, treated at ICU and/or at a ward requiring, high-flow oxygen, radiographic changes and/or a complicated clinical process; and 2) those who are referred from primary care with COVID-19-related symptoms from several organ system that have lasted for at least 3 months and that they are still on sick leave. Those that were discharged to nursing homes are excluded. The out-patient clinic will be

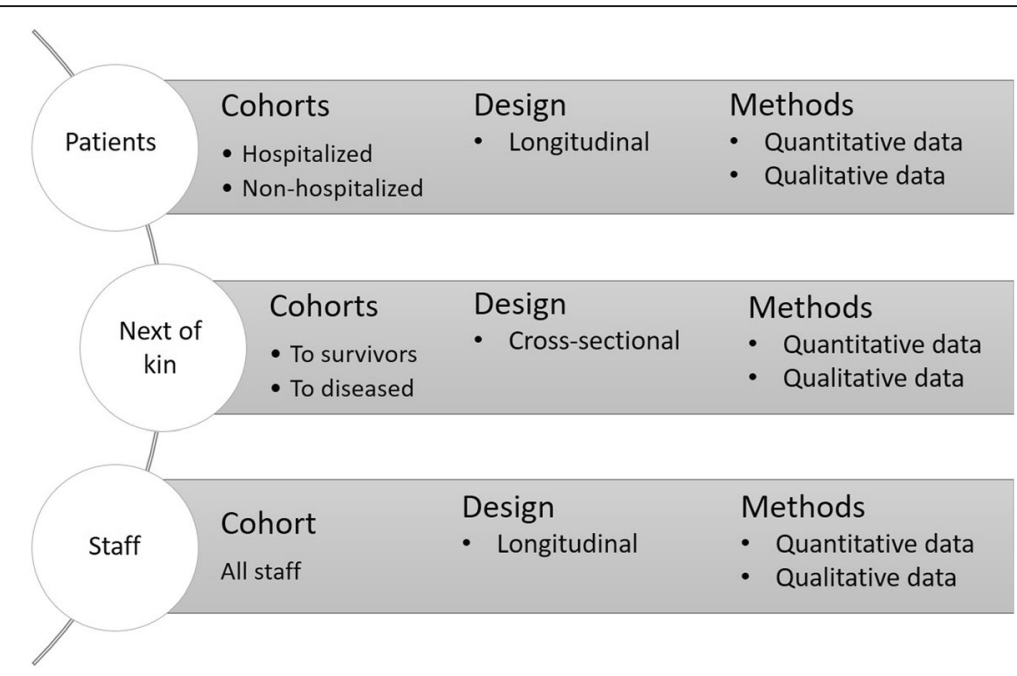

Fig. 1 Description of the cohorts 
Table 1 Overview of measurements used in the different cohorts

\begin{tabular}{|c|c|c|c|}
\hline Variables & Patients & Next of kin & Staff \\
\hline Six-minute walk & $x$ & & \\
\hline Chair-stand & $x$ & & \\
\hline Hand grip strength & $x$ & & \\
\hline Spirometry & $x$ & & \\
\hline Inspiratory and expiratory muscle strength & $x$ & & \\
\hline Activities of daily living & $x$ & & \\
\hline Cognition & $x$ & & \\
\hline Speech and voice & $x$ & & \\
\hline Swallowing and eating & $x$ & & \\
\hline Risk of malnutrition & $x$ & & \\
\hline Hearing and Tinnitus & $x$ & & \\
\hline Health-related Quality of Life & $x$ & $x$ & $x$ \\
\hline Health literacy & $x$ & & \\
\hline Work ability & $x$ & $x$ & $x$ \\
\hline Fatigue & $x$ & $x$ & $x$ \\
\hline Sleeping disorders & $x$ & $x$ & $x$ \\
\hline Anxiety and depression & $x$ & $x$ & $x$ \\
\hline Post-traumatic stress & $x$ & $x$ & $x$ \\
\hline Burn-out & & & $x$ \\
\hline
\end{tabular}

coordinated together with the other departments at the hospital to reduce the burden on the patients.

\section{Assessments}

All patients that consent to participate will be screened and evaluated for physical and cognitive function, activities of daily living and work ability (those who worked before they got the disease), risk of malnutrition, hearing, voice- and swallowing disorders as well as psychosocial support. The following measurements and questionnaires will be used:

- Physical capacity: Six-minute walk (meters completed during $6 \mathrm{~min}$ ) [20]

- Lower extremity strength: Chair stand 30-s and 1 min sit to stand [21]

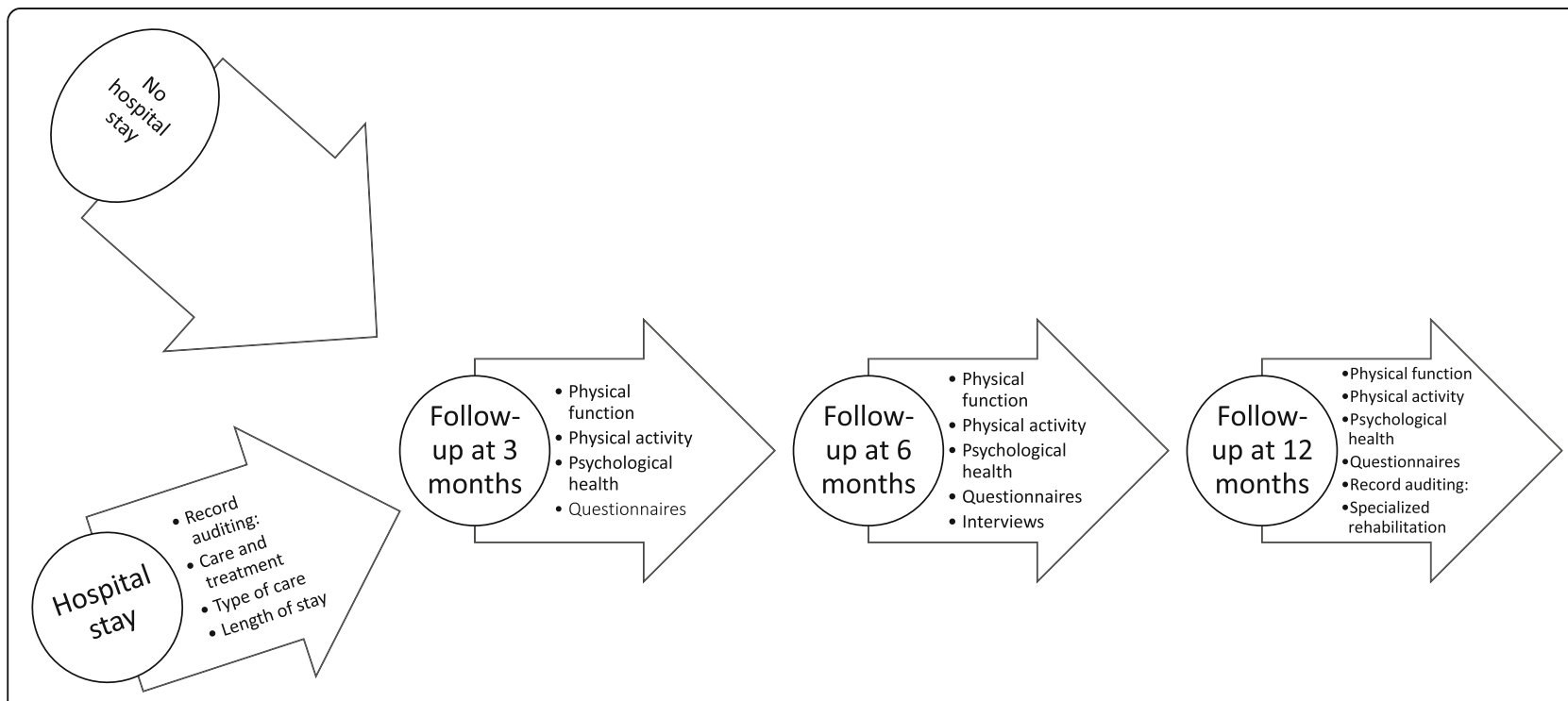

Fig. 2 Process for collecting data in the longitudinal design for the patient cohort 
- Hand grip strength: Jamar Hand dynamometer [22]

- Lung function: Micro-Loop [23]

- Inspiratory and expiratory muscle strength: MicroRPM [24]

- Physical Activity: Frändin/Grimby scale [25] and Accelerometer (ActivePAL) [26]

- Activities of daily living: Canadian Occupational Performance Measure [27]

- Cognitive Function: Montreal Cognitive Assessment (MoCA) [28]

- Speech and voice: Self-assessment of acquired speech disorders (In Swedish: SOFT - Självsvarsformulär om förvärvade talsvårigheter) [29]

- Swallowing, eating and oral motor function: EAT10 [30], Nordic Orofacial Test-Screening [31]

- Screening for risk of malnutrition: Tool developed by the Swedish National Board of Health and Welfare [32]

- Hearing: The Hearing Handicap Inventory for the Elderly [33] and Tinnitus Handicap Inventory [34]

- Health-related Quality of Life: RAND-36 [35] and EQ-5D [36]

- Health literacy: eHEALS [37]

- Work ability: Work Ability Index [38]

- Fatigue: Mental Fatigue Scale [39], Fatigue Severity Scale [40]

- Sleeping disorders: Insomnia Severity Index [41]

- Anxiety and depression: Generalised Anxiety Disorder 7-item scale (GAD-7) [42], The Short Health Anxiety Inventory [43] and Patient Health Questionnaire-9 (PHQ-9) [44]

- Post-traumatic stress symptoms: Posttraumatic Stress Disorder Checklist for DSM-5 (PCL-5) [45], for patients cared for at ICU: Impact of Events Scale-6 (IES-6) [46]

\section{Interviews}

We will explore patients views of treatment, care and rehabilitation as well as their perceptions of psychosocial support, communication between health care professional, patients and next of kin as well as emotional consequences of the disease period. A strategic and purposive sample in consideration to sex, age, sociodemographic factors and disease severity will be invited to participate in semi-structured interviews. The interviews will take place at different time points after onset of disease as well as in relation to the first, second and third wave. A fourth group will consist of non-hospitalized patients. Each group will include approximately 20 participants. The participants will decide if they want a relative present or not.

They will be asked for participation through a letter by mail or with a telephone call. The participants can choose whether they want to be interviewed by phone, digital meeting or a physical meeting at the hospital and the interviews are estimated to take $30-60 \mathrm{~min}$. The interview guide will be piloted during the $2-3$ first interviews and modified if necessary. Transcripts and participation checking will be done if clarifications will be deemed necessary or if the participants request this. Data saturation will be considered during the recruitment period.

The interviewers (men and women) will have different professions, but they are all part of the rehabilitation team and they have previous experience of interviewing in qualitative research studies. The interviewers are employed by the hospital, but they do not have a caregiver- patient relationship. Before consenting to participate, the patients will be informed about the aim of the study and reasons for the interviewer to conduct them, i.e. increase the knowledge about this new disease and its consequences.

\section{The next of kin cohort}

This cross-sectional cohort consists of two groups, one group that had a relative that survived and one with a relative that died. They will be asked to fill out questionnaires about background data such as age, sex as well as health-related quality of life, anxiety, depression, posttraumatic stress, work ability and sleeping disorders (described above) (Table 1). A strategic and purposive sample will be invited to participate in semi-structured interviews to explore their views and perceptions of psychosocial support and communication between health care professional, patients and next of kin.

For the next of kin with relative that died, an information letter and a request for participation will be sent together with the questionnaires. If they return the questionnaires, they consent to participate. A strategic sample of will then be contacted by a medical social worker to ask for consent to participate in an interview and approximately 20 people will be included.

When a patient that has been hospitalized is enrolled in the patient cohort, he/she is asked if we can contact their relatives, approximately 20 people will be included, consecutively. The procedure for enrolling relatives will follow the same procedure as described above.

The participants can choose whether they want to be interviewed by phone, a digital meeting or a physical meeting at the hospital and the interviews are estimated to take $30-60 \mathrm{~min}$. The interview guide will be piloted during the 2-3 first interviews and modified if necessary. Transcripts will be returned to the participants if clarifications will be deemed necessary or if the participants request this. Data saturation will be considered during the recruitment period.

The interviewers (women) will be medical social workers or nurses and they have previous experience of 
interviewing in qualitative research studies. The interviewers are employed by the hospital, but they have not been involved in care or treatment for the next of kin or their relative. Before consenting to participate, the next of kin will be informed about the aim of the study and reasons for the interviewer to conduct them, i.e. increase the knowledge about how this new disease has affected next of kin.

\section{The staff cohort}

A purposive sample of health care staff including nurses, assistant nurses, doctors, and allied health care professionals) working in intensive care units and wards where patients with COVID-19 have been cared for, or in other ways involved in the care of COVID-19 patients, at Karolinska University Hospital will be invited to participate via several internal communication channels (like the intranet, e-mail, and information letters). The study is longitudinal with five data collection points over 1 year.

\section{Assessments}

Assessments are conducted in intervals of 3 months, starting during the third quarter of 2020 , i.e. baseline, and 3, 6, 9 and 12 months following baseline (see Fig. 3). Demographics and background variables (e.g., age, gender, marital status, professional affiliation, specialty, years in the profession, previous periods of mental illness and working conditions during the study period), and information from reliable and validated psychological health self-assessment forms are collected via an electronic platform. In addition to the self-report questionnaires distributed to patient and next of kin we also use the (see also Table 1):

- Burnout: Shirom-Melamed Burnout Questionnaire (SMBQ) [47]

- Coping Strategies: Coping Strategies Questionnaire (CSQ) [48]

\section{Interviews}

A strategic and purposive sample will be invited to participate in semi-structured interviews (individual interviews or focus groups) to explore their views and perceptions of caring for and treating patients with COVID-19. The interview guide will contain question areas about how one experienced the work during the pandemic, important experiences and what has been helpful in the form of staff support efforts, experiences of team work; experiences of existing and needed support and information; and experiences of how communication with colleagues, managers and patients has worked and what support one feels one needs going forward, as well as questions that capture psychological, emotional and practical experiences in relation to caring for patients with COVID-19.

The participants can choose whether they want to be interviewed by phone, digital meeting or a physical meeting at the hospital, and if they want to participate in individual interviews or focus groups. The interviews are estimated to take $30-60 \mathrm{~min}$ and the focus groups $60 \mathrm{~min}$. The interview guides will be piloted during the 2-3 first interviews and modified if necessary. Field notes will be taken during the focus groups. Transcripts will be returned to the participants if clarifications will be deemed necessary or if the participants request this.

The interviewers (men and women) will be psychologists and medical social workers and they have previous experience of interviewing in qualitative research studies. The interviewers are employed by the hospital, but they have not been working together with the respondents. Before consenting to participate, respondents will be informed about the aim of the study and reasons for the interviewer to conduct them, i.e. increase the knowledge about how the pandemic has affected the staff.

When considering the sample size, we have taken into account the following aspects: (a) the aim of the study, (b) sample specificity, (c) use of established theory, (d) quality of dialogue, and (e) analysis strategy as proposed by Malterud et al. 2016 [49] and focused on the information power rather than saturation per se. The following

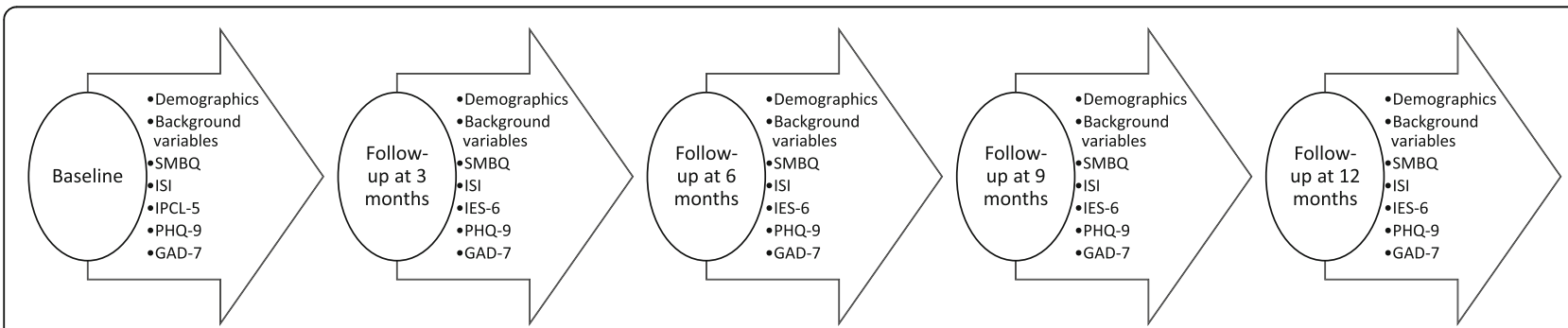

Fig. 3 Process for collecting data in the longitudinal design for the health care staff cohort. Abbreviations: SMBQ Shirom-Melamed burnout questionnaire, IS/ insomnia severity index, PHQ-9 PCL-5 patient health questionnaire-9, GAD-7 generalized anxiety disorder 
factors, specific to this study, have been taken into consideration:

1. The fairly wide scope of the study aim and the topics covered by the semi structured interview guide

2. The sample including staff from different professions, disciplines (doctors, nurses, physiotherapists, psychologists, counselors, health care practitioners, occupational therapists, speech and language pathologists, dietitians etc.)

3. The wide range in demographics in the sample

4. The unique and extreme working environment imposed by the pandemic and the urgent need to capture a large variety in experiences.

These considerations combined has led us to an approximated sample of $80-100$ participants.

\section{Analyses}

Quantitative data will be described with mean (standard deviation), median (inter-quartile range) and proportion as well as parametric and non-parametric analyses depending on data level. Different regression analyses will be used depending on the research question and data level of the outcome measures. The longitudinal data will for example be analysed using Linear Mixed Models that in addition to studying change at the group level also can model change on the individual level, handle dependency for repeated observations and provide correct estimates with missing data.

The interviews will be transcribed in their entirety (verbatim) and analysed through an inductive content analysis that includes the following steps; repeated reading, coding of meaningful passages, categorization and sub-categorization $[49,50]$. Experienced researchers in the project group will be responsible for the coding process and synthesizing the results in the different cohorts (mainly MN-B, LA, LH, MK, EÅ, OD). Mixed method analyses will also be used when combining quantitative and qualitative data.

\section{Preliminary results}

The recruitment process is ongoing, below we describe the process and the recruitment rate so far.

\section{Patient cohort}

So far approximately 1000 patients have been followedup at the out-patient clinic, 750 that were hospitalized and 250 that are referred from primary care. Of those approximately 480 patients have given written informed consent to participate in the study. The 3-months follow-up has recently been finalized with patients from the first wave (March to June 2020). Six-months followup started in January 2021. The second wave (October to January/February 2021) of patients will have their first follow-up starting early spring of 2021. Interviews will start during spring 2021. Patients in the third wave (starting March 2021) will have their first follow-up starting June 2021.

\section{Next of kin cohort}

Due to the second wave of the pandemic, recruitment had to be postponed but will start during late spring 2021.

\section{Staff cohort}

Data collection is ongoing and began in August 2020, 430 staff members from several different professional categories (including nurses, assistant nurses, doctors, and allied health professions) have been included and are followed longitudinally. Analysis of the material collected from baseline will be carried out during the spring of 2021 and analysis of all data points will be carried out in the autumn of 2021. Recruitment to interviews is planned to be carried out during late spring 2021, or as soon as the third wave of the pandemic has mitigated and when healthcare staff are able to participate in interviews. Transcription and analysis of collected material will be carried out in 2022. Work on manuscripts will follow subsequently during 2023.

\section{Discussion}

The rationale of this protocol article is to introduce a three-armed cohort study with the overarching aim to evaluate the consequences of COVID-19 in the perspective of the patients, the next of kin, and the health care staff.

COVID-19 is a new disease so there are large knowledge gaps that need to be filled. The project is highly relevant since the patient may have a slow recovery due to the severity of the disease. Empirical data indicate that the patients are affected on several levels and a rehabilitation period will be necessary to be able to return to their normal life, go back to work and to be able to participate in leisure activities and in the society again. This project will deepen the knowledge about the patient's' recovery, type of specialized rehabilitation as well as the patients and their next of kins' experiences and views of the care- and rehabilitation process. It will also give knew knowledge about how the pandemic has affected psychological health among staff working with patients with COVID-19. The multidisciplinary nature of this project will help to cover the different types of problems that patients might experience and when necessary, patients will be offered specialized rehabilitation at the 
hospital's out-patient clinic or referred to primary care when appropriate.

Several different tests and questionnaires are used in this study. As this is a new disease their psychometric properties have not been tested on this specific patient group. This can be regarded as a limitation. However, they are all tested for different psychometric properties in different patient groups [19-48], which can be regarded as sufficient. The fact that we used somewhat overlapping questionnaires in the three cohorts can be considered a strength since this will give possibilities to compare and evaluate psychological health and work ability across cohorts. The longitudinal design in combination with data retrieved from patient records will give us possibilities to describe, follow and describe the interventions the patients have been given in the clinical practice. Since this is a new disease and the currently available evidence is not sufficient to decide which intervention would be most appropriate to evaluate in a randomized controlled trial, an observational perspective is needed. In addition, the patients are inflicted with different long-term consequences and a multifactorial intervention is therefore most likely necessary. This can also be described and evaluated with an observational design.

In conclusion, this study will be able to answer different research questions both from a quantitative and qualitative perspective, by describing and evaluating long-term consequences and their associations with recovery as well as exploring patients, next of kin and staffs' views and experiences of the pandemic. It will also generate knowledge to design and evaluate different interventions in future randomized controlled trials. This will form a base for a deeper and better understanding of the consequences of the disease from different perspectives (patients, next of kin and health care staff) which in turn will help the society to better prepare for a future pandemic.

\section{Abbreviations \\ ICU: Intensive care unit; MoCA: Montreal Cognitive Assessment; SOFT: Self- assessment of acquired speech disorders (In Swedish: Självsvarsformulär om förvärvade talsvårigheter); EAT10: Eating assessment tool (10 items); RAND- 36: Measure of health-related quality of life; EQ-5D: EuroQol - 5 Dimension; eHEALS: eHEAlth Literacy Scale; GAD-7: Generalised Anxiety Disorder 7-item scale; PHQ-9: Patient Health Questionnaire-9; ISI: Insomnia Severity Index; PCL-5: Posttraumatic Stress Disorder Checklist for DSM-5; IES-6: Impact of Events Scale-6; SMBQ: Shirom-Melamed Burnout Questionnaire; CSQ: Coping Strategies Questionnaire}

\section{Acknowledgements}

We would like to thank Associate professor Judith Bruchenfeld, specialist in infectious diseases and PhD Michael Runold, specialist in pulmonary medicine for great collaboration in planning and organizing the multidisciplinary and multi-professional follow-up clinic integrated in the study about patients in this research project.

\section{Authors' contributions}

All authors were involved in the study design. ER, LH and MNB wrote the first draft of the manuscript. The remaining authors $L A, M R, A M A, Y O, L N, U E$,
$M K, E \AA, O D, R Z, M B$ contributed to writing the manuscript and read and approved its final version. No publications containing the results of this study have already been published or submitted to any journal. The author(s) read and approved the final manuscript.

\section{Funding}

Funding has been granted from the public governmental body FORMAS (government research council for sustainable development) (Dnr 202002789). The application has gone through a peer-review process and funds have been granted in competition with other applicants. In addition, local research funds at the hospital have also contributed to costs for project coordination and the data collection process. Further funding is continuously being applied for. Open Access funding is provided by Karolinska Institute.

\section{Availability of data and materials}

Data is not publicly available due to Swedish and European legislations, but available upon request. Requests for access to the data can be put to our Research Data Office (rdo@ki.se) at Karolinska Institutet and will be handled according to the relevant legislation. This will require a data processing agreement or similar with the recipient of the data.

\section{Declarations}

\section{Ethics approval and consent to participate}

The study follows the Helsinki declaration and is approved by the Swedish Ethical Authorities (Dnr 2020-02149; 2020-03215; 2020-04048; 2020-06039; 2021-01101; 2021-00988). All participants have given written informed consent for participation. Participation is voluntary and participants can cancel their participation at any time.

Patient cohort.

Since this disease results in many different consequences many tests and questionnaires must be used in order to capture the different problems among the patients. To minimize the burden for the patients, most data are collected within the clinical setting and are coordinated with the other involved departments at the hospital.

Next of kin.

Next of kin are also highly affected by the pandemic, therefore it is important to include them in the study from an ethical perspective. However, to ensure patient integrity, the patient decide whether the next of kin will be asked to participate or not. If health-related issues are found in this cohort, they will be referred to relevant professions in primary care. Staff.

Health care staff are invited to participate in the study via a secure digital platform with double authentication, where you register oneself. Participants receive written information about the study when they register and can then give informed consent to participate digitally. All self-estimated data is stored unidentified on a secure server and the material is compiled in such a way that it is not possible to identify the subjects. Privacy protection is considered during storage, processing and compilation.

\section{Consent for publication}

Not applicable.

\section{Competing interests}

The authors declare that they have no competing interests.

\section{Author details}

'Department of Neurobiology, Care Sciences and Society, Division of Physiotherapy, Karolinska Institutet, Huddinge, Sweden. ${ }^{2}$ Women's Health and Allied Health Professionals Theme, Medical Unit Occupational Therapy and Physiotherapy, Karolinska University Hospital, Solna, Sweden. ${ }^{3}$ Women's Health and Allied Health Professionals Theme, Department of Social Work in Health, Karolinska University Hospital, Solna, Sweden. ${ }^{4}$ Department of CLIN TEC, Karolinska Institutet, Stockholm, Sweden. ${ }^{5}$ Department of Neurobiology, Care Sciences and Society, Division of Occupational Therapy, Karolinska Institutet, Huddinge, Sweden. ${ }^{6}$ Women's Health and Allied Health Professionals Theme, Medical Unit Speech and Language Pathology, Karolinska University Hospital, Stockholm, Sweden. ${ }^{7}$ CLINTEC, Division of Speech-Language Pathology, Karolinska Institutet, Stockholm, Sweden. ${ }^{8}$ Perioperative Medicine and Intensive Care Function, Department of Intensive Care, Karolinska University Hospital, Stockholm, Sweden. 
${ }^{9}$ Department of Neurobiology, Care Sciences and Society, Division of Nursing, Karolinska Institutet, Huddinge, Sweden. ${ }^{10}$ Women's Health and Allied Health Professionals Theme, Medical Unit Clinical Nutrition, Karolinska University Hospital, Stockholm, Sweden. ${ }^{11}$ Department of Biosciences and Nutrition, Karolinska Institutet, Stockholm, Sweden. ${ }^{12}$ Department of Clinical Neuroscience, Division of Psychology Karolinska Institutet, Stockholm, Sweden. ${ }^{13}$ Women's Health and Allied Health Professionals Theme, Medical Unit Medical Psychology Karolinska University Hospital, Solna, Sweden. ${ }^{14}$ Department of Psychology, Stress Research Institute, Stockholm University, Stockholm, Sweden. ${ }^{15}$ Department of Neurobiology, Care Sciences and Society, Division of Clinical Geriatrics, Karolinska Institutet, Huddinge, Sweden.

Received: 17 May 2021 Accepted: 10 June 2021

Published online: 30 June 2021

\section{References}

1. World Health Organisation. Report of the WHO-China joint mission on coronavirus disease 2019 (COVID-19). Geneva, Switzerland: World Health Organisation; 2020

2. The Public Health Agency of Sweden (In Swedish: Folkhälsomyndigheten). https://www.folkhalsomyndigheten.se/smittskydd-beredskap/utbrott/a ktuella-utbrott/covid-19/statistik-och-analyser/bekraftade-fall-i-sverige/.

3. Gupta A, Madhavan M, Sehgal K, Nair N, Mahajan S, Sehrawat T, et al. Extrapulmonary manifestations of COVID-19. Nat Med. 2020;26:1017-32.

4. Verity R, Okell LC, Dorigatti I, Winskill P, Whittaker C, Imai N, et al. Estimates of the severity of coronavirus disease 2019: a model-based analysis. Lancet Infect Dis. 2020;3099:1-9.

5. Halpin SJ, Mclvor C, Whyatt G, Adams A, Harvey O, McLean L, et al. Post discharge symptoms and rehabilitation needs in survivors of COVID-19 infection: a cross-sectional evaluation. J Med Virol. 2021:93:1013-22.

6. Belli S, Balbi B, Prince I, Cattaneo D, Masocco F, Zaccaria S, et al. Low physical functioning and impaired performance of activities of daily life in COVID-19 patients who survived the hospitalisation. Eur Respir J. 2020;56(4): 2002096.

7. Goërtz YMJ, Van Herck M, Delbressine JM, Vaes AW, Meys R, Machado FVC, et al. Persistent symptoms 3 months after a SARSCoV-2 infection: the postCOVID-19 syndrome? ERJ Open Res. 2020; in press

8. Caccialanza R, Laviano A, Lobascio F, Montagna E, Bruno R, Ludovisi S. Early nutritional supplementation in non-critically ill patients hospitalized for the 2019 novel coronavirus disease (COVID-19): rationale and feasibility of a shared pragmatic protocol. Nutrition. 2020;74:110835.

9. Cohen BE, Durstenfeld A, Roehm PC. Viral causes of hearing loss: a review for hearing health professionals. Trends Hear. 2014;18:1-17.

10. Pasquale V, Massimo R, Davide P, Donatella M, Domenico S, Luigi M, et al. Tinnitus and equilibrium disorders in COVID-19 patients: preliminary results. Eur Arch Otorhinolaryngol. 2020;23:1-6.

11. Janiri D, Carfi A, Kotzalidis GD, Bernabei R, Landi F, Sani G. Gemelli against COVID-19 post-acute care study group. Persistent symptoms in patients after acute COVID-19. JAMA. 2020;324:603-5.

12. Chung WY, Wong TKS, Chang KKP, Chow CB, Chung BPM, Chung G, et al. Rapid assessment of a helpdesk service supporting severe acute respiratory syndrome patients and their relatives. Respir Nurs. 2004;13:748-55.

13. Lai J, Ma S, Wang Y, Cai Z, Hu J, Wei N, et al. Factors Associated With Mental Health Outcomes Among Health Care Workers Exposed to Coronavirus Disease 2019. JAMA. 2020:3:e203976.

14. Zhu Z, Xu S, Wang H, Liu Z, Wu J, Li G, et al. COVID-19 in Wuhan: sociodemographic characteristics and hospital support measures associated with the immediate psychological impact on healthcare workers. E Clin Med. 2020:24:100443.

15. Rossi R, Socci V, Pacitti F, Di Lorenzo G, Di Marco A, Siracusano A, et al. Mental health outcomes among frontline and second-line health care workers during the coronavirus disease 2019 (COVID-19) pandemic in Italy. JAMA Netw Open. 2020;3:e2010185.

16. Pearman A, Hughes ML, Smith EL, Neupert SD. Mental health challenges of United States healthcare professionals during COVID-19. Front Psychol. 2020:11:2065.

17. Shaukat N, Ali DM, Razzak J. Physical and mental health impacts of COVID19 on healthcare workers: a scoping review. Int J Emerg Med. 2020;13:40.

18. Maunder R. The experience of the 2003 SARS outbreak as a traumatic stress among frontline healthcare workers in Toronto: lessons learned. Philos Trans R Soc Lond Ser B Biol Sci. 2004;359:1117-25.
19. Maunder RG, Lancee WJ, Balderson KE, Bennett JP, Borgundvaag B, Evans $\mathrm{S}$, et al. Long-term psychological and occupational effects of providing hospital healthcare during SARS outbreak. Emerg Infect Dis. 2006;12:1924-32

20. American Thoracic Society. ATS statement: guidelines for the six-minute walk test. Am J Respir Crit Care Med. 2002;166:111e7.

21. Jones CJ, Rikli RE, Beam WC. A 30-s chair-stand test as a measure of lower body strength in community-residing older adults. Res Q Exerc Sport. 1999; 70:113-9.

22. Mathiowetz V, Weber K, Volland G, Kashman N. Reliability and validity of grip and pinch strength evaluations. J Hand Surg Am. 1984;9:222-6.

23. Standardization of Spirometry, 1994 Update. American Thoracic Society. Am J Respir Crit Care Med. 1995:152:1107-36.

24. Dimitriadis Z, Kapreli E, Konstantinidou I, Oldham J, Strimpakos N. Test/retest reliability of maximum mouth pressure measurements with the MicroRPM in healthy volunteers. Respir Care. 2011;56:776-82.

25. Grimby G, Frändin K. On the use of a six-level scale for physical activity. Scand J Med Sci Sports. 2018;28:819-25

26. Edwardson $\mathrm{CL}$, et al. Considerations when using the activPAL monitor in field-based research with adult populations. J Sport Health Sci. 2017; 6:162-78.

27. Law M, Baptiste S, Carswell A, McColl MA, Polatajko H, Pollock N. Canadian occupational performance measure (COPM). 5th ed; 2019.

28. Nasreddine ZS, Phillips NA, Bedirian V, Charbonneau S, Whitehead V, Collin I, et al. The Montreal cognitive assessment, MoCA: a brief screening tool for mild cognitive impairment. Altona: COPM Inc. J Am Geriatr Soc. 2005;53:695-9.

29. Hartelius LD. Dysarthria - assessment and intervention, self-assessment of acquired speech disorders (in Swedish: Dysartri - bedömning och intervention, SOFT). Lund: Studentlitteratur; 2015.

30. Möller R, Safa S, Östberg P. Validation of the Swedish translation of eating assessment tool (S-EAT-10). Acta Otolaryngol. 2016;136:749-53.

31. Bakke M, Bergendal B, McAllister A, Sjögreen L, Ågren P. Development and evaluation of a global screening for orofacial dysfunction. Swedish Dental J. 2007;2:75-84.

32. Socialstyrelsen. Att förebygga och behandla undernäring. Kunskapsstöd i hälso-och sjukvård och socialtjänst. Stockholm. [In Swedish]. 2020

33. Ventry IM, Weinstein BE. The hearing handicap inventory for the elderly: a new tool. Ear Hear. 1982;3:128-34.

34. Newman CW, Sandridge SA, Jacobson GP. Psychometric adequacy of the tinnitus handicap inventory (THI) for evaluating treatment outcome. J Am Acad Audiol. 1998;9:153-60.

35. Orwelius $L$, Nilsson $M$, Nilsson $E$, Wenemark $M$, Walfridsson $U$, Lundström $M$ et al. The Swedish RAND-36 health survey - reliability and responsiveness assessed in patient populations using Svensson's method for paired ordinal data. J Patient Rep Outcomes. 2017:2:4.

36. Burstrom K, Sun $S$, Gerdtham UG, Henriksson M, Johannesson M, Levin LA, et al. Swedish experience-based value sets for EQ-5D health states. Qual Life Res. 2014;23:431-42.

37. Wångdahl J, Jaensson M, Dahlberg K, Nilsson U. The Swedish version of the electronic health literacy scale: prospective psychometric evaluation study including thresholds levels. JMIR mHealth uHealth. 2020:8(1):e16316.

38. IImarinen J. The work ability index (WAI). Occup Med. 2007;57:160

39. Johansson B, Starmark A, Berglund P, Rödholm M, Rönnbäck L. A selfassessment questionnaire for mental fatigue and related symptoms after neurological disorders and injuries. Brain Inj. 2010;24:2-12.

40. Mattsson M, Möller B, Lundberg I, Gard G, Boström C. Reliability and validity of the fatigue severity scale in Swedish for patients with systemic lupus erythematosus. Scand J Rheumatol. 2008;37:269-77.

41. Bastien $\mathrm{CH}$, Vallieres $\mathrm{A}$, Morin $\mathrm{CM}$. Validation of the insomnia severity index as an outcome measure for insomnia research. Sleep Med. 2001;2:297-307.

42. Spitzer RL, Kroenke K, Williams JW, Löwe B. A brief measure for assessing generalized anxiety disorder: the GAD-7. Arch Int Med. 2006;166:1092-7.

43. Salkovskis PM, Rimes KA, Warwick HMC, Clark DM. The health anxiety inventory: the development and validation of scales for the measurement of health anxiety \& hypochondriasis. Psychol Med. 2020;32:843-53.

44. Kroenke K, Spitzer RL, Williams JBW. The PHQ-9: validity of a brief depression severity measure. J Gen Intern Med. 2001:16:606-13.

45. Blevins CA, Weathers FW, Davis MT, Witte TK, Domino JL. The posttraumatic stress disorder checklist for DSM-5 (PCL-5): development and initial psychometric evaluation. J Trauma Stress. 2015;28:489-98. 
46. Thoresen S, Tambs K, Hussain A, Heir T, Johansen VA, Bisson Jl. Brief measure of posttraumatic stress reactions: impact of event scale-6. Soc Psychiatry Psychiatr Epidemiol. 2010;45:405-12.

47. Melamed S, Ugarten U, Shirom A, Kahana L, Lerman Y, Froom P. Chronic burnout, somatic arousal and elevated cortisol levels. J Psychosom Res. 1999:46:591-8.

48. Jensen IB, Linton SJ. Coping strategies questionnaire (CSQ): reliability of the Swedish version of the CSQ. Scand I Behav Ther. 1993;22:139-45.

49. Malterud K, Siersma VD, Guassora AD. Sample size in qualitative interview studies: guided by information power. Qual Health Res. 2016;26:1753-60

50. Elo S, Kääriäinen M, Kanste O, Pölkki T, Utriainen K, Kyngäs H. Qualitative content analysis: a focus trustworthiness. SAGE Open. 2014;4(1): 215824401452263 .

\section{Publisher's Note}

Springer Nature remains neutral with regard to jurisdictional claims in published maps and institutional affiliations.

Ready to submit your research? Choose BMC and benefit from:

- fast, convenient online submission

- thorough peer review by experienced researchers in your field

- rapid publication on acceptance

- support for research data, including large and complex data types

- gold Open Access which fosters wider collaboration and increased citations

- maximum visibility for your research: over $100 \mathrm{M}$ website views per year

At BMC, research is always in progress.

Learn more biomedcentral.com/submissions 